\title{
Heteroplasmy of the cytochrome b Gene in Venturia inaequalis and Its Involvement in Quantitative and Practical Resistance to Trifloxystrobin
}

\author{
Sara M. Villani and Kerik D. Cox
}

Department of Plant Pathology and Plant-Microbe Biology, New York State Agricultural Experiment Station, Cornell University, Geneva 14456. Accepted for publication 19 February 2014.

\begin{abstract}
Villani, S. M., and Cox, K. D. 2014. Heteroplasmy of the cytochrome b gene in Venturia inaequalis and its involvement in quantitative and practical resistance to trifloxystrobin. Phytopathology 104:945-953.

Quantitative (partial) and qualitative (complete) resistance responses to quinone outside inhibitor (QoI) fungicides have been documented for the apple scab pathogen Venturia inaequalis. Resistance monitoring efforts have traditionally focused on the detection of qualitative resistance based on a single point mutation, G143A, within the cytochrome b (cyt b) gene. In order to better understand the role of heteroplasmy of the $c y t b$ gene in the QoI resistance response for isolates and populations of $V$. inaequalis, an allele-specific quantitative polymerase chain reaction was developed to quantify the relative abundance of the A143 (resistant) allele in 45 isolates of $V$. inaequalis with differing in vitro resistance responses to the QoI fungicide trifloxystrobin. Although a high relative abundance of the A143 allele ( $>62 \%)$ was associated with isolates with high resistance responses (50 to $100 \%$ relative growth on trifloxystrobin-amended medium), heteroplasmy of the $c y t b$ gene was not the primary factor in-

volved in isolates with moderate resistance responses (29 to $49 \%$ relative growth). The relative abundance of the A143 allele in isolates with moderate resistance to trifloxystrobin rarely exceeded $8 \%$, suggesting that other resistance mechanisms are involved in moderate resistance and, therefore, that the Qol resistance response is polygenic. In research orchards where QoI fungicides failed to control apple scab (practical resistance), field trials were conducted to demonstrate the link between practical resistance and the abundance of the A143 allele. Relative abundance of the A143 allele in these orchard populations exceeded $20 \%$ in 2011 and 2012. Similarly, of the eight additional commercial orchards screened in 2011, the relative abundance of the A143 allele always exceeded 20\% in those with QoI practical resistance. Although heteroplasmy of the $c y t b$ gene did not entirely explain the response of isolates with moderate resistance to QoIs, the relative abundance of A143 in orchard populations of $V$. inaequalis helps to explain the point of emergence for practical resistance to trifloxystrobin across several orchard populations with differing production histories.
\end{abstract}

Apple scab, caused by the pathogen Venturia inaequalis (Cooke) G. Winter, is one of the most devastating diseases of apple in the northeastern United States $(34,35)$. In the absence of durable resistance in most of the commercially desirable apple cultivars, fungicides provide the only means for controlling apple diseases $(34,36)$. Because of the polycyclic nature of apple scab coupled with the temperate climate of the northeastern United States, which results in cool, humid weather during spring and early summer, apple growers must apply fungicides $\geq 10$ times per season to control the disease $(24,35)$. The use of modern sitespecific fungicide chemistries such as sterol demethylation inhibitors (DMIs, 1980s) and quinone outside inhibitors (QoIs, late 1990s) has enabled apple producers to manage apple scab and many other key fungal diseases (i.e., cedar apple rust and powdery mildew) while minimizing harmful effects on nontarget organisms and to the environment (21-23,25,27,43). Unfortunately, because these fungicides are single-site inhibitors (i.e., they block a single biochemical pathway in fungi), repetitive use has selected for the emergence of resistant $V$. inaequalis populations in the apple production regions east of the Mississippi throughout the last half of the 20th century. Such was the case for dodine resistance in the late 1960 s $(15,47)$, benzimidazole resistance in the 1970s, $(15,16,19)$, and DMI resistance in the early 1990s (25). Since the turn of the 21st century, concerns of

Corresponding author: K. D. Cox; E-mail address: kdc33@ cornell.edu

http://dx.doi.org/10.1094/PHYTO-06-13-0158-R

(c) 2014 The American Phytopathological Society widespread practical resistance to the DMI fungicides have led to greater reliance on QoI fungicides to manage apple scab in this region. Practical resistance is defined as the point within the quantitative resistance continuum where applications of the fungicide result in greatly diminished levels of disease control under field conditions (20). Not long after their introduction, isolates of $V$. inaequalis with QoI resistance were discovered in an orchard in Michigan (23) and, by 2009, widespread resistance to QoI fungicides was documented in $V$. inaequalis populations from commercial apple orchards in Michigan $(3,27)$. Although QoI resistance in $V$. inaequalis developed rapidly in Michigan $(3,27)$, there have been few reports of resistance to QoIs in orchards from apple-producing regions in the eastern United States $(4,12)$.

QoI fungicides inhibit mitochondrial respiration by binding to the outer quinone-oxidizing pocket of the cytochrome $b_{1}$ enzyme complex III. This binding inhibits electron transfer in the respiratory pathway, which terminates cellular respiration and, thus, the production of ATP $(2,13,21)$. One of the most common mechanisms of QoI resistance described for fungal pathogens is a single point mutation at amino acid position 143 within the cytochrome $b$ (cyt b) gene. This mutation results in a change from glycine to alanine (G143A) and seems to impart a qualitative, vertical, or complete resistance response, whereby isolates are highly resistant to QoI fungicides (23). The presence of this single-nucleotide polymorphism (SNP) in cyt $b$ has been consistently associated with qualitative resistance responses to QoI fungicides in a number of fungal pathogens $(2,7,10,17,48)$, including $V$. inaequalis $(4,8,23,27,40,49,50)$. For the remainder of this article, we will use 
the terms "qualitative resistance" to refer to an isolate with a complete resistance phenotype and "qualitative resistance response" to refer to any response imparted by the presence of one or more mitochondria with the G143A cyt $b$ gene mutation. Other point mutations within the cyt $b$ gene at amino acid position 129, where phenylalanine is exchanged with leucine (F129L), and at position 137, where glycine is replaced by argenine (G137R), have been shown to confer diminished QoI sensitivity in fungal pathosystems $(13,17,18,41,44,45)$. However, none of these or other mutations have been reported in V. inaequalis $(8,27,37)$.

In addition to the qualitative resistance response, there appears to be a quantitative (polygenic or partial) resistance response to QoI fungicides (23), whereby isolates display a range of sensitivity phenotypes when exposed to doses of QoIs below the point at which the alternative respiration pathway becomes activated $(6,40)$. Such in vitro responses are regarded as quantitative for an individual isolate. For the remainder of this article, we will use the terms "quantitative resistance" and "quantitative resistance response" to refer to the collection of factors working in concert that are responsible for an isolate's response to QoI fungicides. We will also use these terms to refer to an isolate's overall phenotypic response to QoI fungicides in vitro.

Although quantitative responses are typically explained by the involvement of several genes with minor contributions to an overall phenotype, differences in the ratios of mutant (resistant, A143) to wild-type (sensitive, G143) copies of the cyt $b$ gene could also account for the way that $V$. inaequalis isolates within a population express quantitative resistance to trifloxystrobin. Populations with varying ratios of A143 to G143 are described as having heteroplasmy of the $c y t b$ gene, and this phenomenon has been described for several fungal pathogens, including $V$. inaequalis $(3,10,18,26,27,30,37,50)$. However, none of these studies have addressed the contribution of $c y t b$ heteroplasmy to the quantitative resistance response for individual isolates or attempted to relate the abundance of the A143 allele in a field population to the development of practical resistance to QoI fungicides. It has been suggested that practical resistance to QoI fungicides in orchard populations of $V$. inaequalis develops when the population transitions from isolates with quantitative resistance to isolates with qualitative (complete) resistance (23). However, we suspect that practical resistance may appear when the relative abundance or frequency of the A143 (resistant) allele for a given field population of $V$. inaequalis exceeds some undefined threshold for the QoI fungicide in question.

A quantitative approach such as allele-specific quantitative polymerase chain reaction (AS-qPCR) could be useful for investigating the role of heteroplasmy of the $c y t b$ gene in quantitative resistance responses for individual isolates and the subsequent development of practical resistance in field populations. AS-qPCR has already been used for detecting and quantifying QoI resistance in Blumeria graminis f. sp. tritici in wheat (10), Alternaria spp. infecting pistachio (29,31-33), and even $V$. inaequalis (37). Quantification of the relative amounts of the $c y t b$ A143 allele may help explain the apparent quantitative resistance responses of $V$. inaequalis isolates to QoI fungicides in vitro (23). In addition, quantifying the relative abundance of the A143 allele in an orchard population may improve our understanding of the development of practical resistance. The goal of this study was to develop a better understanding of the role of $c y t b$ heteroplasmy in resistance to QoI fungicides for isolates and populations of the apple scab pathogen $V$. inaequalis. Specifically, we wished to use AS-qPCR to detect and quantify $c y t b$ heteroplasmy in monoconidial isolates, thereby allowing us to examine the contribution of the A143 allele to the quantitative resistance response to trifloxystrobin. We also conducted field trials and surveys in conjunction with $c y t b$ AS-qPCR to learn how qualitative resistance responses are involved in the development of practical resistance for orchard populations of $V$. inaequalis.

\section{MATERIALS AND METHODS}

Collection of $\boldsymbol{V}$. inaequalis isolates and the determination of quantitative resistance to trifloxystrobin in vitro. In total, 45 monoconidial isolates of $V$. inaequalis that represented the scope of typical QoI fungicide sensitivity responses were selected to examine heteroplasmy of the $c y t b$ gene in regards to the G143A mutation. These isolates were collected from 12 commercial apple orchards in the northeastern United States and from two baseline orchards in western New York that had never been directly exposed to QoIs or other modern fungicide chemistries (e.g., DMIs, guanidines, or benzimidazoles). The selected isolates were obtained from apple scab lesions originating from infections on young, fully expanded leaves and were phenotyped for quantitative resistance to the QoI fungicide trifloxystrobin using a modified microscopy-aided mycelial relative growth assay previously described and validated (23). Briefly, individual sporulating lesions were removed using a sterile cork borer $(5 \mathrm{~mm}$ in diameter) and stored in a dry, sterile $1.5-\mathrm{ml}$ microcentrifuge tube at room temperature for no longer than 3 months. Prior to fungicide sensitivity evaluation, conidia were separated from the lesion by shaking the disc in $1 \mathrm{ml}$ of sterile distilled water for $60 \mathrm{~s}$. The leaf discs were promptly removed and $100-\mu$ suspensions of $V$. inaequalis at $10^{3}$ to $10^{4}$ conidia $\mathrm{ml}^{-1}$ were evenly distributed on potato dextrose agar (PDA) (Difco Laboratories, Detroit) amended with streptomycin sulfate $\left(50 \mu \mathrm{g} \mathrm{ml}^{-1}\right)$, chloramphenicol $(50 \mu \mathrm{g}$ $\mathrm{ml}^{-1}$ ), and analytical-grade trifloxystrobin (TR medium) (Sigma Aldrich, St. Louis) at a discriminatory dose of $0.02 \mu \mathrm{g} \mathrm{ml}^{-1}$, as suggested by Köller et al. (23). Additionally, 100- $\mu$ conidial suspensions were distributed on PDA amended only with streptomycin sulfate and chloramphenicol (PDA++) as a control. Isolates were incubated at $22^{\circ} \mathrm{C}$ for 6 days, and mycelial growth of five randomly selected microcolonies was determined by measuring microcolony diameter or germ tube length using a SPOT Idea digital camera with the SPOT Imaging Basic software package (Diagnostic Instruments Inc., Sterling Heights, MI) attached to an Olympus SZX12 stereoscope (Olympus America Inc., Center Valley, PA). The quantitative resistance response for each isolate was expressed as mean percent relative growth (\%RG), as previously described (23). To determine a qualitative resistance phenotype, conidia from each isolate were also placed on a medium amended with trifloxystrobin in the presence of salicylhydroxamic acid (SHAM) (trifloxystrobin at $0.2 \mu \mathrm{g} \mathrm{ml}^{-1}$ and SHAM at $\left.100 \mu \mathrm{g} \mathrm{ml} \mathrm{g}^{-1}\right)(\mathrm{TR}+\mathrm{S}$ medium) and were evaluated for the emergence of $V$. inaequalis microcolonies following 14 days of incubation, as previously described (23).

Extraction of genomic DNA and molecular detection of the G143A cyt $\boldsymbol{b}$ gene mutation by direct sequencing. To preserve their QoI resistance phenotypes prior to DNA extraction, monoconidial isolates with mean RGs $>29 \%$ on TR medium were maintained as colonies on PDA amended with a low dose of trifloxystrobin $\left(0.02 \mu \mathrm{g} \mathrm{ml}^{-1}\right)$ while baseline and sensitive isolates were maintained on PDA. To assess whether or not the low dose of trifloxystrobin $\left(0.02 \mu \mathrm{g} \mathrm{ml}^{-1}\right)$ in the medium greatly influenced the relative copy number of isolates with RGs $>29 \%$, nine representative isolates in the category were also grown on unamended PDA. Following incubation for 8 weeks at $22^{\circ} \mathrm{C}$ on PDA medium, $\approx 200 \mathrm{mg}$ of mycelium from each isolate was ground in liquid nitrogen using a mortar and pestle. DNA extraction was accomplished using the Omega Bio-Tek Plant DNA Kit (Omega BioTek, Norcross, GA), according to the manufacturer's instructions.

To determine the presence of the $c y t b$ G143A mutation in each isolate, $V$. inaequalis cyt $b$ specific primers ViCytB-5F (5'-GGA CCA AGT AAT CAC TGG TGT ATG G-3') and ViCytB-6071R (5'-TTG AAA GCT AGG CTA GGG CGA ACA-3') (4) were used to generate a 938-bp amplicon that included codon 143, and these were used for direct sequencing. PCR reactions were performed in 25- $\mu$ l reaction volumes and contained $1 \times$ PCR buffer, 
$0.4 \mu \mathrm{M}$ each primer, $2.5 \mathrm{mM} \mathrm{MgCl} 2,200 \mu \mathrm{M}$ each $\mathrm{dNTP}, 0.625 \mathrm{U}$ of GoTaq Flexi DNA polymerase (Promega Corporation, Madison, WI), and $5 \mathrm{ng}$ of genomic DNA. Amplifications were performed using an iCycler thermal cycler (Bio-Rad Laboratories Inc., Hercules, CA) with the following program: $3 \mathrm{~min}$ at $94^{\circ} \mathrm{C}$; 30 cycles of $30 \mathrm{~s}$ at $94^{\circ} \mathrm{C}, 30 \mathrm{~s}$ at $55^{\circ} \mathrm{C}$, and $30 \mathrm{~s}$ at $72^{\circ} \mathrm{C}$; followed by a final extension step of $5 \mathrm{~min}$ at $72^{\circ} \mathrm{C}$. PCR products were separated on a $2 \%$ agarose gel (Bio-Rad Laboratories Inc.) stained with ethidium bromide, in $1 \times$ Tris-acetate-EDTA buffer at $100 \mathrm{~V}$ for $1 \mathrm{~h}$. Photographs of the gel were taken on a KODAK Gel Logic 200 Imaging System (Eastman Kodak Company, Rochester, NY). PCR products were purified using the QiaQuick PCR Purification Kit (Qiagen, Valencia, CA) and were sequenced with primer ViCytB-1F (5'-AGA GCA ACG AGT AGA CGG TAG T-3') (4) using an Applied BioSystems Automated 3730xl DNA Analyzer at the Cornell University DNA Sequencing facility in Ithaca, NY.

AS-qPCR amplification. The abundance of A143 allele (resistant) copies relative to the total $c y t b$ abundance (A143 + G143 alleles) was determined by performing qPCR using two primer sets in a manner similar to that described by Ma et al. (32). Primers VIcytbF (5'-GAG TAG ACG GTA GTT AAT GTA TTC AT- $\left.3^{\prime}\right)$ and VIcytbINT-R (5'-ACG GTA TAG CAC TCA TAA GGT TTG-3') were designed using the published sequence of the $V$. inaequalis cyt $b$ gene (GenBank accession number AF004559) to obtain an optimized fragment for qPCR that would detect both the G143 and A143 alleles in V. inaequalis isolates. An optimized fragment for detecting only the A143 allele in $V$. inaequalis isolates was created using forward primer VIR-F (5'-GAC TAT CGC GTA TCT AAA TCA TAT A-3') and reverse primer G143AMM4 (5'-GGT TTG TGA TGA CAG TTG GAG-3'), the latter having been designed for AS-PCR for the detection of QoIresistant (QoI-R) V. inaequalis isolates in France (9). Amplifications for qPCR were performed with the Bio-Rad CFX96 Touch Real-Time PCR Detection System (Bio-Rad Laboratories Inc.), using a SYBR Green I fluorescent dye detection system (Bio-Rad Laboratories Inc.). Amplifications were conducted in a $25-\mu \mathrm{l}$ reaction volume and contained $12.5 \mu \mathrm{l}$ of iQ SYBR Green Supermix ( $1 \times$ final concentration), $1 \mu \mathrm{l}$ each of primers VIcytb-F and VIcytbINT-R or of primers VIR-F and G143AMM4 $(0.4 \mu \mathrm{M}$ final concentration), and $1 \mu \mathrm{l}(5 \mathrm{ng})$ of DNA template using the following program: $3 \mathrm{~min}$ at $94^{\circ} \mathrm{C}$ and 40 cycles of $94^{\circ} \mathrm{C}$ for $15 \mathrm{~s}$, $64^{\circ} \mathrm{C}$ for $25 \mathrm{~s}$, and $68^{\circ} \mathrm{C}$ for $30 \mathrm{~s}$. Three technical replicates were included for each isolate and the experiment was repeated.

As previously suggested by Ma et al. (32), abundance of the A143 allele relative to the abundance of both G143 + A143 alleles in each sample was determined from standard curves using a set of serial dilutions of DNA from a highly resistant isolate as a quantitative comparison standard (positive control). In this instance, a standard curve was generated for the two qPCR primer pairs VIcytb-F/VIcytbINT-R and VIR-F/G143AMM4 using 10-

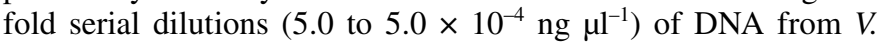
inaequalis isolate number 11-1-10, which was highly resistant to trifloxystrobin in vitro (no inhibition of growth on trifloxystrobin at 0.02 or $0.2 \mu \mathrm{g} \mathrm{l}^{-1}$ ). Additionally, a non-template control and a trifloxystrobin-sensitive baseline isolate (number 3-50-10) were included to detect any false-positive amplification by primer pair VIR-F and G143AMM4. Data were analyzed with Bio-Rad CFX Manager software (version 2.1). The mean abundance of the resistant allele for each isolate was determined from three (technical) replicate qPCR reactions for the resistant allele (A143) relative to corresponding replicate $\mathrm{qPCR}$ reactions for the sensitive and resistant alleles (G143 + A143) (32).

Determination of thresholds for practical resistance to trifloxystrobin and quantification of A143 alleles for an orchard with QoI resistance in $\boldsymbol{V}$. inaequalis. To verify and establish standards for populations with trifloxystrobin practical resistance, field trials were performed in a research orchard at the New York
State Agricultural Experiment Station in Geneva, NY in 2011 and 2012. The orchard contains 15-year-old 'Empire' apple on M.9/M.111 interstem rootstocks and has a long history of DMI and QoI fungicide use. Treatment programs used to verify practical resistance consisted of either (i) four applications of Flint 50WG (trifloxystrobin; Bayer CropScience, Cary, NC) at the maximum labeled rate of $140 \mathrm{~g} / \mathrm{Ha}$, (ii) four applications of Inspire (difenoconazole; Syngenta, Greensboro, NC) at the maximum labeled rate of $293 \mathrm{ml} / \mathrm{Ha}$, or (iii) no fungicide applications (untreated). All fungicides were applied in $\approx 2,800$ liters of water per hectare using an AA2 GunJet handgun (TeeJet Technologies, Wheaton, IL) at $\approx 2,000 \mathrm{kPA}$ pressure. The four applications for each fungicide treatment were made at 7- to 10-day intervals at the phenological stages of pink, bloom, first cover, and second cover. Plots sprayed with trifloxystrobin or difenoconazole also received additional applications of protectant (nonselective) fungicides when trees were at green tip, half-inch green, tight cluster, and petal fall. These additional applications consisted of captan (2.8 kg/Ha) (Captan 80 WDG; Arysta LifeScience Company, Cary, NC) mixed with mancozeb $(3.3 \mathrm{~kg} / \mathrm{Ha}$ ) (Penncozeb 75DF; United Phosphorus Inc., King of Prussia, PA). All plots received a standard insecticide and weed management program but did not receive applications of fruit thinners or growth regulators for retaining apple fruit. Treatments were arranged in a randomized block design with four replications. Scab inoculum consisted of natural leaf litter on the orchard floor. Incidence of mature Empire fruit with apple scab lesions was determined at harvest in 2011 and 2012 by evaluating 10 subsamples of five fruit from each of the four replicates per treatment. All incidence data were subject to arcsine square root transformation to stabilize treatment variances. Transformed incidence data were then subjected to analysis of variance for a randomized block design using generalized linear mixed models with the GLIMMIX procedure of SAS (version 9.3; SAS Institute Inc., Cary, NC).

The abundance of individual $V$. inaequalis isolates and the overall population abundance of qualitative resistance responses as determined by the cyt $b$ A143 allele were evaluated for the research orchard population in both years of the field trial. Each year, 50 fully expanded leaves with young sporulating apple scab lesions were collected, and two $V$. inaequalis apple scab lesions from each of these leaves were excised as described previously (23). From each of the 50 leaves, one of the two leaf lesions was evaluated for QoI sensitivity using the $\mathrm{TR}+\mathrm{S}$ conidial emergence assay as described above (23). To assess qualitative resistance responses using AS-qPCR, we also employed a pooled sampling scheme similar to that of other protocols for monitoring orchard population sensitivity in $V$. inaequalis $(32,37,44)$. Specifically, the remaining 50 excised lesions (one lesion from each leaf) were pooled and then divided randomly into two replicate composite samples (25 lesions per sample). Each sample was ground in $\approx 25 \mathrm{ml}$ of liquid nitrogen prior to DNA extraction, and AS-qPCR was performed on the resulting samples as described above. The relative abundance of the A143 allele for the orchard population was determined for three replicate AS-qPCR reactions and the two replicate composite leaf samples as described above.

Quantification of the QoI qualitative resistance response in orchard populations of $\boldsymbol{V}$. inaequalis. In total, eight orchard populations from New York and New England were selected for evaluation. Three of the orchards were reported to have populations with practical resistance to QoI fungicides (K. D. Cox, unpublished data), while the remaining five populations included two baseline populations and three from orchards where apple scab has been successfully managed with QoI fungicides. The two baseline populations were from old, isolated plantings that have never been exposed to QoIs or to other modern fungicides (e.g., DMIs or benzimidazoles). The QoI qualitative resistance responses for orchard populations of $V$. inaequalis demonstrating practical resistance were assessed using the conidial germination 
assay and AS-qPCR as described above. Relationships between the frequencies of isolates determined to possess qualitative resistance by the conidial germination assay on $\mathrm{TR}+\mathrm{S}$ agar and the relative abundance of the A143 allele in the composite samples were examined by regression analysis using SAS (version 9.3; SAS Institute, Inc.).

\section{RESULTS}

Evaluation of quantitative and qualitative resistance to trifloxystrobin for $\mathbf{4 5}$ monoconidial isolates of $\boldsymbol{V}$. inaequalis from the northeastern United States. Across all isolates selected to represent the range of QoI sensitivity phenotypes, the quantitative resistance response, expressed as mean \% RG on media amended with trifloxystrobin at $0.02 \mu \mathrm{g} \mathrm{ml}^{-1}$, was 0.0 to $134.8 \%$. Baseline isolates, as expected, failed to grow at this discriminatory concentration. Amplification using PCR primers ViCytB$5 \mathrm{~F}$ and ViCytB-6071R yielded an anticipated 938-bp fragment for all $V$. inaequalis isolates regardless of their in vitro sensitivity to trifloxystrobin (Fig. 1). Sequencing of PCR products with primer $\mathrm{ViCytB}-1 \mathrm{~F}$ revealed a single point mutation at amino acid position 143 of the $V$. inaequalis cyt $b$ gene (GGT/glycine to GCT/ alanine) in 24 isolates (Table 1). In some isolates with the QoI-R genotype, evidence of heteroplasmy could be observed in sequencing electropherograms (Fig. 2). As expected, there was concordance between the direct sequencing method and the conidia emergence assay $(\mathrm{TR}+\mathrm{S})$ for the determination of qualitative

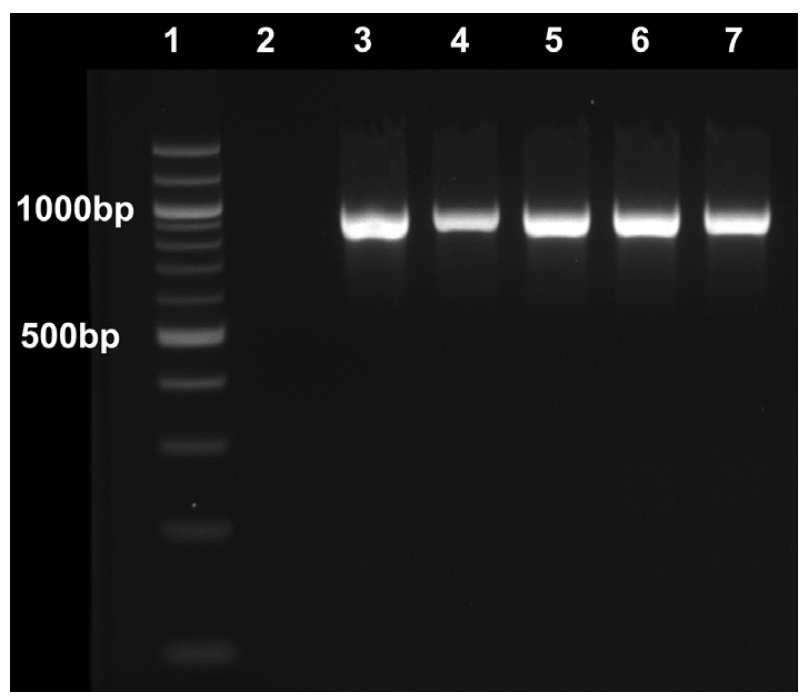

Fig. 1. Results from amplification of a 938-bp fragment in the Venturia inaequalis cytochrome $b$ gene for which the amplified product contained the region of the G143A mutation. Lane 1, Quick-Load 100-bp DNA Ladder (New England BioLabs); lane 2, non-template control; lanes 3 to 7, $V$. inaequalis isolates with increasing quantitative resistance responses to trifloxystrobin (isolate numbers 3-50-10, 11-19-10, 37-23-10, 11-10a-11, and 14-38-10, respectively).

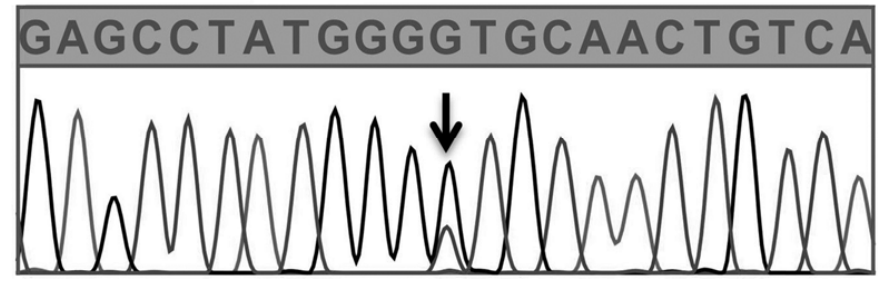

Fig. 2. Electropherogram illustrating heteroplasmy at amino acid position 143 of the Venturia inaequalis cytochrome $b$ gene. Guanine $(\mathrm{G})$, represented by the higher peak immediately below the arrow, is the most abundant nucleotide at position 143; however, cytosine (C) is also detected at the same position. resistance (data not shown). For the 24 isolates with the QoI-R genotype, the quantitative resistance response (\%RG) was 40.3 to $134.8 \%$, with a mean of $90.23 \pm 4.6 \%$, whereas those with the QoI-sensitive (QoI-S) genotype had \% RG values of 0.0 to $48.5 \%$, with a mean of $23.44 \pm 4.6 \%$.

Quantification of the A143 allele in monoconidial isolates of V. inaequalis using AS-qPCR. Primers VIcytb-F and VIcytbINT$\mathrm{R}$ designed for qPCR amplified a 216-bp fragment for $V$. inaequalis isolates with either the QoI-S or QoI-R genotype. Sequencing of PCR products generated by this primer set yielded results at amino acid position 143 that were identical to those achieved using primers ViCytB-5F and ViCytB-6071R in traditional PCR amplification and direct sequencing (data not shown). Allele-specific primers VIR-F and G143AMM4 produced a 244-bp fragment for $V$. inaequalis isolates confirmed to have the QoI-R genotype (Fig. 3). These primers failed to amplify a product for isolates with the QoI-S genotype (Fig. 3), and those isolates had little to no growth on TR-amended medium or conidia emergence on $\mathrm{TR}+\mathrm{S}$ amended medium. All primer sets failed to amplify Penicillium expansum, an out-group fungus often isolated on apple scab lesions in addition to $V$. inaequalis (Fig. 3). Independent standard curves were generated using Bio-Rad CFX Manager software (version 2.1) for qPCR primer sets VIcytb-F/VIcytbINT-R and VIR-F/G143AMM4. For both primer sets, detection of the targeted region in the cyt $b$ gene was achieved for $V$. inaequalis concentrations of $\geq 5 \times$ $10^{-4} \mathrm{ng} \mu \mathrm{l}^{-1}$.

The relative abundance of the resistant allele (A143) in monoconidial $V$. inaequalis isolates was 0 to $100 \%$ (Table 1). Isolates which only possessed sensitive G143 allele failed to grow on medium amended with trifloxystrobin, with the exception of isolate number 11-48-10, which had a mean \%RG value of $41.9 \%$. By comparison, isolates homoplastic for the resistant A143 allele had qualitative resistance and displayed a high quantitative resistance response in vitro, indicated by $\% \mathrm{RG}$ values of 81.2 to $134.8 \%$ (Fig. 4). Approximately two-thirds of isolates tested (31 of 45) demonstrated heteroplasmy of the $c y t b$ gene, having copies of both resistant and sensitive alleles. Among the isolates demonstrating heteroplasmy, there was a wide range in quantitative resistance responses ranging from completely sensitive $(0 \%$ RG) to completely resistant ( $\geq 100 \%$ RG) (Fig. 4). Moreover, the relative abundance for isolates with mean $\mathrm{RGs}>29 \%$ on TR medium that were cultured initially on both TR medium and unamended PDA was not significantly different from one to the other $(P>0.05)$ (data not shown).

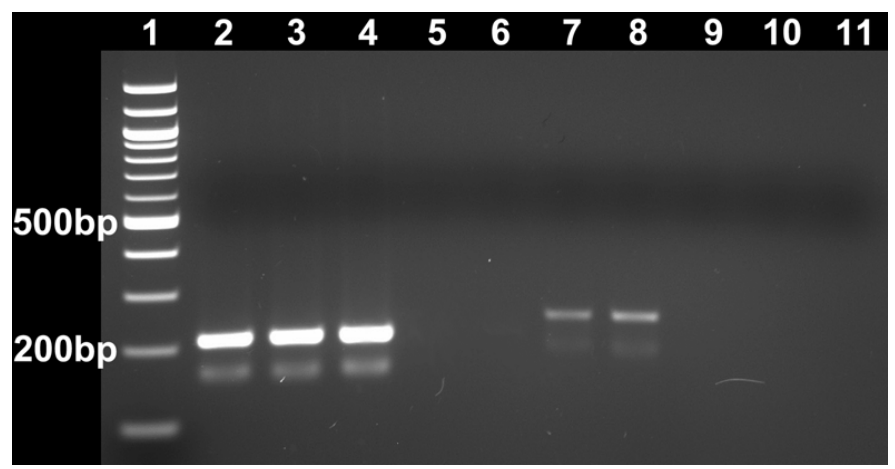

Fig. 3. Allele-specific polymerase chain reaction amplification of the cytochrome $b$ G143A allele for Venturia inaequalis quinone outside inhibitor (QoI)-resistant and QoI-sensitive isolates: lanes 2 to 6, primers VIcytb-F and VIcytbINT-R; and lanes 7 to 11, VIR-F and G143AMM4. Lane 1, Quick-Load 100-bp DNA Ladder (New England BioLabs); lanes 2 and 7, trifloxystrobinresistant isolate number 14-38-10; lanes 3 and 8 , trifloxystrobin-resistant isolate number 6-47-10; lanes 4 and 9, trifloxystrobin-sensitive isolate number 3-50-10; lanes 5 and 10, Penicillium expansum; and lanes 6 and 11, nontemplate control. 
Overall, there was no clear relationship between the relative abundance of the A143 allele and the quantitative resistance response to trifloxystrobin expressed as \%RG (Fig. 5). For example, even when RG of isolates on TR-amended medium was as high as $40 \%$, the relative abundance of the A143 allele was 0.0 to $0.17 \%$ and, thus, likely did not contribute to higher quantitative resistance responses. For the majority of isolates examined, it wasn't until the quantitative resistance response exceeded $50 \%$ $\mathrm{RG}$ that the relative abundance of the A143 allele was observed to exceed $60 \%$ (Fig. 5). Similarly, nearly all of the isolates with $>50 \%$ RG were found to contain the G143A mutation using direct PCR and sequencing (Table 1).

Determination of thresholds for practical resistance to trifloxystrobin and quantification of A143 alleles for an orchard with QoI resistance to $\boldsymbol{V}$. inaequalis. In field trials to verify and establish standards for populations with practical resistance, trifloxystrobin failed to provide a level of apple scab control comparable with the difenoconazole standard. Both trifloxy- strobin and difenoconazole were applied at maximum labeled rates and identical timings, were subject to identical infection periods, and received identical fungicide cover programs in both 2011 and 2012. In each year, trifloxystrobin was significantly ( $P$ $<0.0001)$ less effective in managing apple scab infections on mature fruit compared with the difenoconazole standard. The incidence of apple scab symptoms on mature fruit consistently exceeded $40 \%$ compared with difenoconazole, which had $<15 \%$ incidence of symptoms on mature fruit in both years. Although trifloxystrobin failed to provide a level of control comparable with that of difenoconazole, both fungicides still had significantly $(P<0.0001)$ less apple scab than the untreated check, which exceeded $84 \%$ incidence in both years (Table 2 ).

Not surprisingly, given the failure of trifloxystrobin to provide a level of control similar to that of difenoconazole, $>35 \%$ of the $V$. inaequalis isolates collected from the research orchard were found to the have qualitative resistance, as determined by conidial germination on TR+S in 2011 and 2012 (Table 3). In addition, the

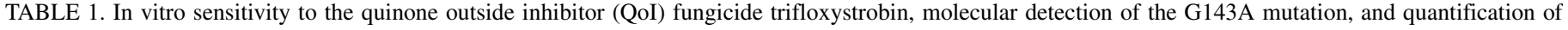
the resistant A143 allele in northeastern United States Venturia inaequalis isolates collected in 2010 and 2011

\begin{tabular}{|c|c|c|c|c|c|c|}
\hline Year & County, state & Orchard designation & Isolate & Mean $\% \mathrm{RG}^{\mathrm{x}}$ & Genotype of cytochrome $b^{\mathrm{y}}$ & Relative abundance $(\%)^{\mathrm{z}}$ \\
\hline 2010 & Ontario, NY & RS10 & $14-38-10$ & $101.19 \pm 19.1$ & A143 & 100.00 \\
\hline 2010 & Ontario, NY & RS10 & $14-37-10$ & $84.46 \pm 7.6$ & A143 & 100.00 \\
\hline 2010 & Ontario, NY & RS10 & $14-4-10$ & $107.94 \pm 3.5$ & A143 & 83.94 \\
\hline 2010 & Ontario, NY & DA10 & $11-27-10$ & $39.81 \pm 1.9$ & G143 & 0.01 \\
\hline 2010 & Ontario, NY & DA10 & $11-48-10$ & $41.93 \pm 5.3$ & G143 & 0.00 \\
\hline 2010 & Ontario, NY & DA10 & $11-45-10$ & $65.33 \pm 3.1$ & A143 & 82.59 \\
\hline 2010 & Ontario, NY & DA10 & $11-19-10$ & $28.83 \pm 3.1$ & G143 & 0.11 \\
\hline 2010 & Ontario, NY & DA10 & $11-39-10$ & $0.00 \pm 0.0$ & G143 & 0.08 \\
\hline 2010 & Ontario, NY & DA10 & $11-28-10$ & $90.13 \pm 0.0$ & A143 & 100.00 \\
\hline 2010 & Ontario, NY & DA10 & $12-19-10$ & $84.41 \pm 7.0$ & A143 & 71.07 \\
\hline 2010 & Ontario, NY & DA10 & $12-26-10$ & $33.60 \pm 2.0$ & G143 & 0.17 \\
\hline 2010 & Ontario, NY & DA10 & $12-5-10$ & $45.00 \pm 27.8$ & G143 & 0.11 \\
\hline 2010 & Ontario, NY & DA10 & $8-33-10$ & $96.27 \pm 18.7$ & A143 & 62.71 \\
\hline 2010 & Ontario, NY & DA10 & $27-35-10$ & $98.75 \pm 8.4$ & A143 & 98.28 \\
\hline 2010 & Ulster, NY & HVL-Pond & $28-16-10$ & $0.00 \pm 0.0$ & G143 & 0.00 \\
\hline 2010 & York, ME & McDSan & $37-23-10$ & $38.07 \pm 2.7$ & G143 & 0.01 \\
\hline 2010 & York, ME & McDSan & $37-20-10$ & $0.00 \pm 0.0$ & G143 & 0.00 \\
\hline 2010 & Ontario, NY & Lakeview & $41-9-10$ & $45.58 \pm 8.1$ & G143 & 7.75 \\
\hline 2010 & Ontario, NY & Lakeview & $41-3-10$ & $90.18 \pm 4.5$ & A143 & 88.27 \\
\hline 2010 & Ontario, NY & Lakeview & $41-2-10$ & $81.21 \pm 12.1$ & A143 & 100.00 \\
\hline 2010 & Ontario, NY & Lakeview & $41-11-10$ & $101.53 \pm 3.9$ & A143 & 90.94 \\
\hline 2010 & Adams, PA & DocPA2 & $47-18-10$ & $134.82 \pm 10.4$ & A143 & 100.00 \\
\hline 2010 & Tompkins, NY & $\mathrm{LT} 2$ & $6-47-10$ & $92.81 \pm 11.2$ & A143 & 93.12 \\
\hline 2010 & Tompkins, NY & LT2 & $6-12-10$ & $92.26 \pm 5.7$ & A143 & 100.00 \\
\hline 2010 & Tompkins, NY & LT2 & $6-40-10$ & $90.50 \pm 7.3$ & A143 & 93.30 \\
\hline 2010 & Ulster, NY & HVL-M9 & $29-23-10$ & $38.28 \pm 21.7$ & G143 & 0.03 \\
\hline 2010 & Tompkins, NY & LT1 & $5-1-10$ & $81.79 \pm 11.4$ & A143 & 100.00 \\
\hline 2010 & Ontario, NY & GFB-BL & $3-17-10$ & $0.00 \pm 0.0$ & G143 & 0.04 \\
\hline 2010 & Ontario, NY & GFB-BL & $3-27-10$ & $0.00 \pm 0.0$ & G143 & 0.00 \\
\hline 2010 & Ontario, NY & GFB-BL & $3-28-10$ & $0.00 \pm 0.0$ & G143 & 0.00 \\
\hline 2010 & Ontario, NY & GFB-BL & $3-50-10$ & $0.00 \pm 0.0$ & G143 & 0.00 \\
\hline 2010 & Ontario, NY & GFB-BL & $3-35-10$ & $0.00 \pm 0.0$ & G143 & 0.01 \\
\hline 2011 & Franklin, MA & VV & 11-10a-11 & $50.88 \pm 2.6$ & A143 & 87.40 \\
\hline 2011 & Franklin, MA & VV & $11-11 a-11$ & $83.86 \pm 14.2$ & A143 & 71.43 \\
\hline 2011 & Franklin, MA & VV & $11-13-11$ & $100.63 \pm 6.5$ & A143 & 98.27 \\
\hline 2011 & Franklin, MA & VV & $11-17-11$ & $72.80 \pm 3.3$ & A143 & 98.60 \\
\hline 2011 & Franklin, MA & VV & $11-1-11$ & $132.65 \pm 14.8$ & A143 & 88.34 \\
\hline 2011 & Franklin, MA & VV & $11-22-11$ & $46.93 \pm 4.7$ & G143 & 0.02 \\
\hline 2011 & Franklin, MA & VV & $11-20-11$ & $66.50 \pm 4.7$ & A143 & 87.65 \\
\hline 2011 & Franklin, MA & VV & $11-25-11$ & $40.27 \pm 5.4$ & A143 & 40.26 \\
\hline 2011 & Franklin, MA & VV & $11-8 a-11$ & $48.45 \pm 3.2$ & G143 & 0.01 \\
\hline 2011 & Oxford, ME & King & $28-17-11$ & $41.46 \pm 17.1$ & G143 & 0.20 \\
\hline 2011 & Penobscot, ME & GAMac & $37-22-11$ & $44.36 \pm 16.2$ & G143 & 1.68 \\
\hline 2011 & Tompkins, NY & LT & $5-44-11$ & $124.23 \pm 0.0$ & A143 & 100.00 \\
\hline 2011 & Ontario, NY & Traver & $32-11-11$ & $0.00 \pm 0.0$ & G143 & 0.02 \\
\hline
\end{tabular}

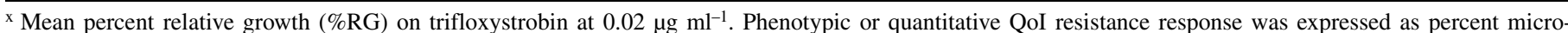
colony growth on medium amended with analytical-grade trifloxystrobin relative to that on non-fungicide amended medium. Values are means and standard errors of five randomly selected single conidium microcolonies for each isolate.

y Genotype of the cytochrome $b$ gene at codon 143 as determined by direct polymerase chain reaction (PCR) and sequencing.

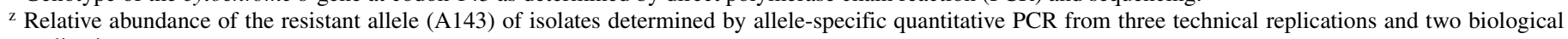
replications. 
relative abundance of the A143 allele in the composite samples collected from this research orchard exceeded $20 \%$, on average, in 2011 and 2012 (Table 3).

Quantification of QoI qualitative resistance responses in orchard populations of $\boldsymbol{V}$. inaequalis. Across the selected baseline and commercial orchards, the percentage of $V$. inaequalis isolates with qualitative resistance to trifloxystrobin, as determined by the conidial germination assay, was 0 to $100 \%$, and the relative abundance of the A143 allele in composite samples was 0.3 to $50.6 \%$ (Table 3 ). Although the ranges were different, there was concordance between the frequency of isolates with qualitative resistance and relative abundance of the A143 allele in composite samples as indicated by a significant and strong linear relationship $\left(R^{2}=0.989, P<0.0001\right)$. For orchards that were not reported to have practical resistance, $<25 \%$ of the $V$. inaequalis population had qualitative resistance determined by conidial germination on $\mathrm{TR}+\mathrm{S}$, and the relative abundance of the A143 allele was $<2 \%$. In orchards that were reported to have practical resistance to trifloxystrobin, $>35 \%$ of the isolate population had qualitative resistance determined by conidial germination on $\mathrm{TR}+\mathrm{S}$, and the relative abundance of the A143 allele in composite samples always exceeded $20 \%$. Although we were unable to evaluate QoI resistance in vitro for orchard $12 \mathrm{~B}$ due to the poor viability of conidia, the relative abundance of the A143 allele in orchard 12B $(22.8 \%)$ exceeded the $20 \%$ relative abundance threshold associated with the practical resistance standards RS11 and RS12.

\section{DISCUSSION}

Monitoring the development of qualitative resistance to QoI fungicides in $V$. inaequalis populations throughout the New York and New England region has been done via conidial germination assays, direct PCR and sequencing of the G143A region of the $c y t b$ gene, and, recently, AS-PCR $(3,5,9,27,29,31)$. Because these methods are designed to detect a single genotype, the contribution of heteroplasmy of the mitochondrial cyt $b$ gene (50) is often disregarded, thereby limiting our understanding of isolate and orchard population genotypes and phenotypes. Indeed, heteroplasmy of the $c y t b$ gene may contribute to the apparent quanti-

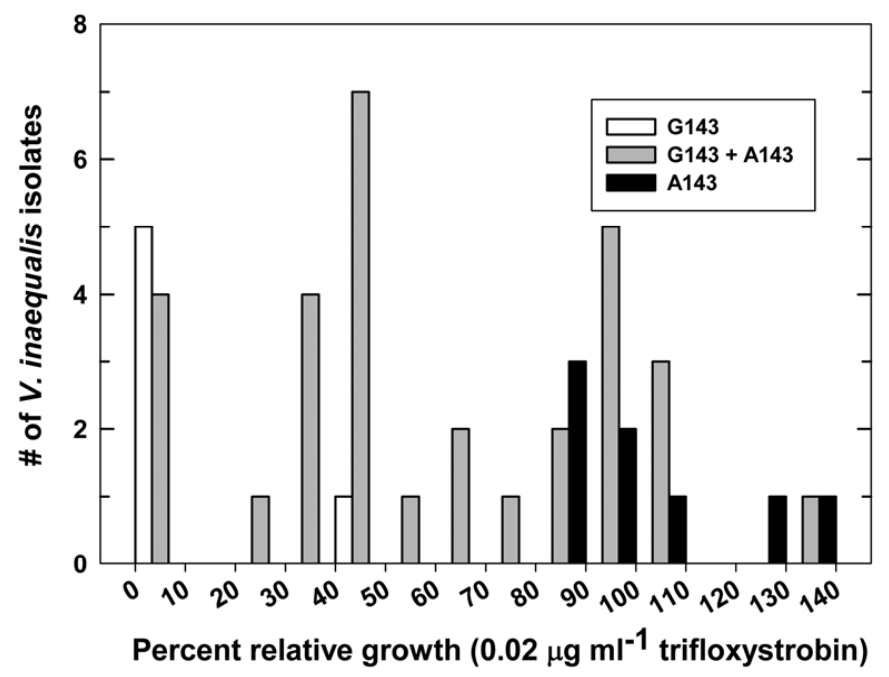

Fig. 4. Distribution of quantitative resistance responses to trifloxystrobin for 45 Venturia inaequalis isolates for each cytochrome $b$ gene genotype at codon 143 as determined by allele-specific quantitative polymerase chain reaction and sequencing. Bars represent the total number of isolates with only the G143 genotype (white bars), only the A143 genotype (black bars), or isolates with G143A heteroplasmy (gray bars). Bars are differentially positioned within a bin to allow for visual discrimination, not to imply a specific subset of percent relative growth values within a bin. tative resistance response to QoI fungicides in $V$. inaequalis (23). We developed an AS-qPCR assay to determine how the relative abundance of the $c y t b$ A143 allele resulting from $c y t b$ gene heteroplasmy contributes to the quantitative resistance response in single conidial isolates and how it relates to the phenomenon of practical resistance in orchard populations of $V$. inaequalis.

In this study, all of the isolates confirmed to have qualitative resistance according to conidial germination on $\mathrm{TR}+\mathrm{S}$ medium (23) were found via DNA sequencing to contain the amino acid substitution from glycine to alanine at codon 143 of the $c y t b$ gene (G143A mutation). In fungi, this point mutation has long been associated with qualitative resistance to QoI fungicides $(4,7,14$, 45,50). Indeed, 60 to $100 \%$ of $V$. inaequalis isolates in Michigan apple orchards with documented QoI fungicide control failures were recently found to have qualitative resistance (27). We observed practical resistance in a research orchard when $>35 \%$ of the isolates in the $V$. inaequalis population were found to have the G143A mutation on the basis of conidial germination. Because losses in QoI fungicide efficacy have long been associated with the development of qualitative resistance in isolates on the basis of conidial germination and PCR restriction fragment length polymorphism or DNA sequencing $(3,9,23,27,28)$, we anticipated that the majority of individual isolates screened would be homoplastic for wild-type or mutant $c y t b$ genes. However, only a third of the isolates screened possessed absolute homoplasmy and these isolates had either qualitative resistance with high resistance responses ( $>81 \%$ RG on TR medium) or were completely sensitive and had no growth (with the exception of isolate number 11-4810) on TR medium. The majority of isolates screened demonstrated some degree of $c y t b$ heteroplasmy and demonstrated a range of quantitative trifloxystrobin resistance responses in vitro. Approximately half of the heteroplasmic isolates were found to possess the G143A mutation as determined by DNA sequencing and, for some isolates, the presence of both alleles could be observed on the electropherograms.

Although heteroplasmy of the $V$. inaequalis $c y t b$ gene was present in many of the isolates evaluated, isolates with quantitative resistance responses exceeding $50 \% \mathrm{RG}$ on TR medium were consistently observed only when the relative abundance of the A143 allele exceeded 62\%, suggesting that A143 abundance is an important contributor to high resistance responses. In regard to isolates with moderate resistance responses to QoI fungicides (29 to $49 \% \mathrm{RG})$, heteroplasmy of the $c y t b$ gene was not the primary

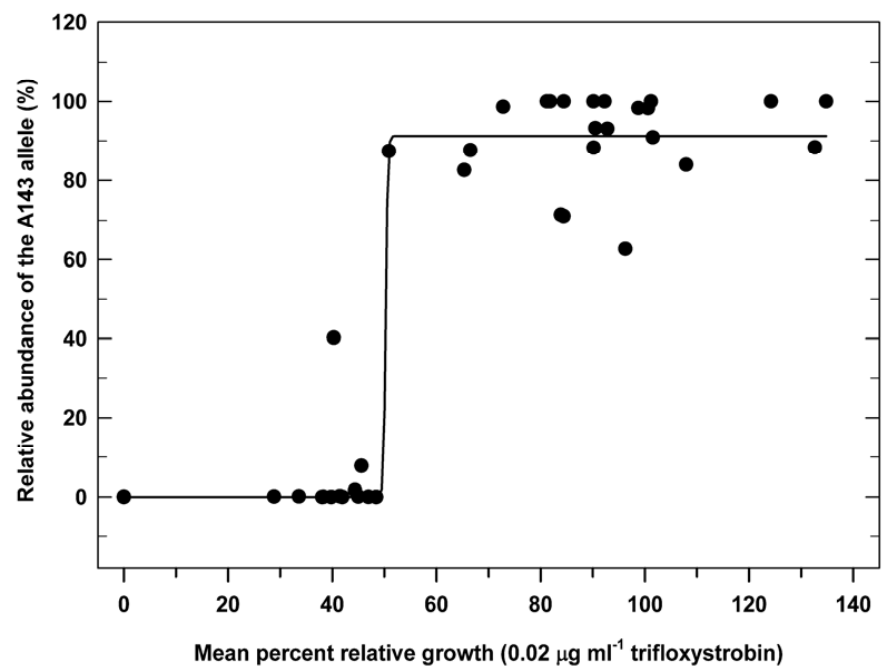

Fig. 5. Relative abundance of the resistant allele determined by allele-specific quantitative polymerase chain reaction for 45 Venturia inaequalis isolates with a range in quantitative resistance responses to trifloxystrobin. The presence of the line is to illustrate the shape of the relationship, not to imply a regression analysis. 
factor involved in the quantitative resistance response. In such isolates, the relative abundance of the A143 allele never exceeded $8 \%$. The low relative abundance of the Al43 allele in several isolates with \%RG values approaching 50\% suggests that other unidentified genetic factors may better explain the quantitative resistance response in some isolates. Interestingly, isolate number 11-25-11 had an A143 relative abundance and $\approx 40 \%$ RG on TR medium. For this isolate, it is possible that high A143 abundance explains the quantitative resistance response in vitro. However, this conclusion cannot be determined for certain because the contributions of other unidentified genetic factors $(7,23)$ potentially involved in the trifloxystrobin resistance response have not been quantified. Similar to the present study, Michalecka et. al. (37) was able to quantify the relative abundance of the A143 allele at the individual level but they only quantified mixtures of DNA from homoplastic isolates rather than using field isolates of $V$. inaequalis with differing quantitative resistance responses. Furthermore, it is still not known whether mitochondrial heteroplasmy plays a role in the quantitative resistance responses to QoI fungicides in other systems. In studies investigating mitochondrial cyt $b$ heteroplasmy in other pathosystems $(11,26,32)$, either there is no apparent quantitative response to QoI fungicides or the relationship between heteroplasmy and quantitative resistance response was not examined or discussed.

Although we found that a high relative abundance of the A143 allele $(>60 \%)$ was associated with high resistance responses $(>50 \% \mathrm{RG})$ to trifloxystrobin, additional resistance mechanisms are likely involved in the resistance responses of both highly resistant isolates and isolates with of low to moderate resistance responses and low A143 allele abundance. The involvement of other genes and resistance mechanisms in QoI insensitivity in vitro has been well documented in other pathogens (7). For example, in Aspergillus nidulans, drug efflux proteins from the ATP-binding cassette transporter family (1) have been found to actively transport fungicides, including strobilurins, out of the fungal cell membrane; whereas, in Mycosphaerella graminicola, the major facilitator superfamily transporters serve the same function (42). A mechanism such as a multidrug efflux pump is certainly plausible in $V$. inaequalis, because multiple drug resistance between QoI and DMI fungicides has previously been documented in the pathogen $(3,38)$. An alternative explanation for the moderate quantitative resistance responses in the absence of the A143 allele is the involvement of the alternative respiration pathway in vitro. In $V$. inaequalis, however, the activation of this pathway has been demonstrated to be highly dependent on strobilurin dose (39), with an increased likelihood of it becoming activated at higher doses. The discriminatory concentration of trifloxystrobin used in the absence of SHAM was specifically selected to monitor the quantitative resistance response (23) without being high enough to trigger the alternative respiration pathway. Hence, it is unlikely that the alternative respiration pathway is the reason for a quantitative resistance response in the absence of a high abundance of the resistant allele. Finally, the presence of other $c y t b$ gene mutations known to be associated with loss of QoI efficacy could account for quantitative resistance in the absence of the A143 allele. In this study, neither the F129L nor the G137R mutations, which have been associated with moderate resistance responses in other pathosystems $(2,13,18,41,44)$, were detected in any of the $V$. inaequalis isolates surveyed (data not shown).

In addition to being able to determine the relative abundance of the A143 allele for individual isolates of $V$. inaequalis, the application of the AS-qPCR technique for orchard composite samples $(37,44)$ allows one to assess the abundance of the A143

TABLE 2. Incidence of apple scab symptoms on mature 'Empire' fruit in 2011 and 2012 from a research orchard at Geneva, NY, where treatments were designed to assess practical resistance to quinone outside inhibitor (QoI) fungicides

\begin{tabular}{lccc}
\hline & & \multicolumn{2}{c}{ Mature fruit scab $(\%)^{\mathrm{z}}$} \\
\cline { 2 - 4 } Treatment programs (amount/ha) & Timing & 2011 & 2012 \\
\hline Untreated & N/A & $93.2 \pm 1.4 \mathrm{a}$ & $84.6 \pm 4.8 \mathrm{a}$ \\
Penncozeb 75DF $(3.3 \mathrm{~kg})+$ Captan 80WDG $(2.6 \mathrm{~kg})$ & $1-3,6$ & $46.2 \pm 5.6 \mathrm{~b}$ & $37.3 \pm 5.8 \mathrm{~b}$ \\
Flint 50WG $(140 \mathrm{~g})$ & $4,5,7,8$ & $1-3,6$ & $10.0 \pm 1.6 \mathrm{c}$ \\
Penncozeb 75DF $(3.3 \mathrm{~kg})+$ Captan 80WDG $(2.6 \mathrm{~kg})$ & $4,5,7,8$ & $10.0 \pm 4.6 \mathrm{c}$ \\
Inspire $(293 \mathrm{ml})$ &
\end{tabular}

y Applications for each year were made at roughly 7 - to 10 -day intervals that corresponded to the following phenological stages: $1=$ green tip, $2=$ half-inch green, $3=$ tight cluster, $4=$ pink, $5=$ bloom, $6=$ petal fall, $7=$ first cover, and $8=$ second cover.

${ }^{\mathrm{z}}$ All values are the mean percent incidence and standard errors of apple scab lesions on mature 'Empire' fruit, expressed as the number of fruit with apple scab lesions out of five collected fruit, with 10 such collections assessed for each of four replicates. Values within columns followed by the same letter are not significantly different $(P \leq 0.05)$ according to LSMEANS procedure of SAS (version 9.3; SAS Institute, Inc., Cary, NC).

TABLE 3. Detection and quantification of the A143 allele associated with trifloxystrobin resistance for apple scab lesions on leaves for Venturia inaequalis populations with and without practical resistance to quinone outside inhibitor (QoI) fungicides

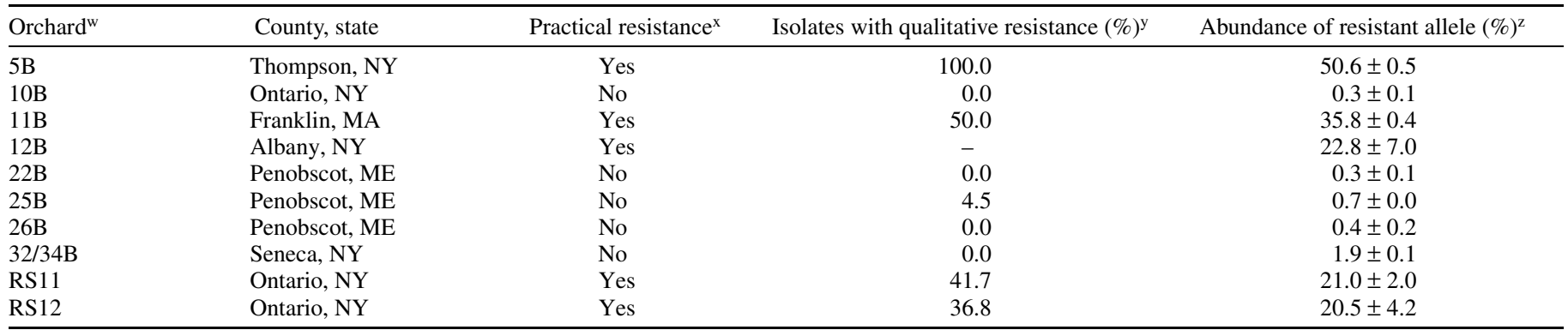

${ }^{\mathrm{w}}$ Orchard designation. RS11 and RS12 are the research orchard populations from which practical resistance was evaluated.

${ }^{x}$ Practical resistance to QoI fungicides.

y The frequency of $V$. inaequalis isolates in an orchard $(n=50)$ determined to have the G143A mutation by conidial germination on media amended with trifloxystrobin at $0.2 \mu \mathrm{g} \mathrm{ml}^{-1}$ and salicylhydroxamic acid at $100 \mu \mathrm{g} \mathrm{ml}^{-1}$; - indicates that qualitative QoI resistance on the basis of conidial germination could not be determined in vitro due to low viability of conidia.

${ }^{\mathrm{z}}$ Relative abundance of the resistant allele (A143) for orchard populations determined by allele-specific quantitative polymerase chain reaction. Values are means and standard errors of three technical replications and two biological replicates, with $25 \mathrm{~V}$. inaequalis lesions per replicate. 
allele for an entire orchard population of $V$. inaequalis. In regards to practical resistance, the relative abundance of the A143 allele was as low as $20 \%$ in the research orchard, where trifloxystrobin failed to provide acceptable levels of apple scab control in 2011 and 2012. This suggested threshold was further verified with composite samples of sensitive and practically resistant orchards in the current study, because no commercial orchards with practical resistance to QoI fungicides had a relative abundance of the A143 allele $<22 \%$. Similarly, Michalecka et al. (37) were able to quantify the abundance of the Al43A allele using AS-qPCR on composite samples from field populations of $V$. inaequalis. Unfortunately, the authors only looked at the abundance of the A143 allele in organic and conventionally managed orchard populations outside of the context of QoI resistance. The authors did report that the abundance of the A143 allele was 50 to $100 \%$ in conventionally managed orchard populations but the QoI resistance status for these orchards was not reported. Although we are unable to validate or explain our A143 frequency threshold using the work of Michalecka et al. (37), the results from our study would suggest that these orchard populations in Poland could have practical resistance.

In conclusion, the results of this study demonstrate that heteroplasmy of the cyt $b$ gene does play a role in the quantitative resistance response in highly resistance isolates. However, the low abundance of the A143 allele in isolates with moderate resistance responses (29 to 49\%RG) suggests that the QoI resistance response is truly multigenic, although the importance of other genes for resistance becomes masked as qualitative resistance when the abundance of the A143 allele is sufficiently high $(>62 \%$ ). Beyond understanding the mechanism of $c y t b$ heteroplasmy in regards to QoI insensitivity, there are implications for evaluating and monitoring the development of practical resistance using A143 allele abundance. Because it is possible to detect and quantify low abundances of the A143 allele using AS-qPCR in orchard composite samples, it would be possible to identify orchards at risk for practical resistance to QoI fungicides, and prevent the development of practical resistance by removing the selective agent prior to the point where the population reaches the $20 \%$ A143 threshold.

\section{ACKNOWLEDGMENTS}

This work was supported, in part, by funds appropriated to New York State Agricultural Experiment Station, Cornell University. We thank W. Köller and D. Parker for providing the authors training on many of the techniques utilized in the microbiological assays of the study and for providing useful advice on the analysis and interpretation of data; G. Koehler, J. Raes, C. Lehman, J. Freier, and K. Abbot for their assistance in the collection, preparation, and evaluation of isolates over the years; and D. Rosenberger for his critical reading of and editing contributions to this manuscript.

\section{LITERATURE CITED}

1. Andrade, A. C., del Sorbo, G., Van Nistelroy, J. G. M., and de Waard, M. A. 2000. The ABC transporter AtrB from Aspergillus nidulans mediates resistance to all major classes of fungicides and some natural toxic compounds. Microbiology 146:1987-1997.

2. Bartlett, D. W., Clough, J. M., Godwin, J. R., Hall, A. A., Hamer, M., and Parr-Dobrzanski, B. 2002. The strobilurin fungicides. Pest Manage. Sci. 58:649-662.

3. Chapman, K. S., Sundin, G. W., and Beckerman, J. L. 2011. Identification of resistance to multiple fungicides in field populations of Venturia inaequalis. Plant Dis. 95:921-926.

4. Cox, K. D., Russo, N. L., Villani, S. M., Parker, D. M., and Köller, W. 2008. QoI qualitative resistance and CYP51A1 upstream anomalies in NY populations of the apple scab pathogen Venturia inaequalis. (Abstr.) Phytopathology 98:S42.

5. Delye, C., Laigret, F., and Corio-Costet, M.-F. 1997. A mutation in the $14 \alpha$-demethylase gene of Unicola necator that correlates with resistance to a sterol biosynthesis inhibitor. Appl. Environ. Microbiol. 63:29662970
6. Färber, R. B., Chin, K. M., and Leadbitter, N. 2002. Sensitivity of Venturia inaequalis to trifloxystrobin. Pest Manage. Sci. 58:261-267.

7. Fernández-Ortuño, D., Torés, J. A., de Vicente, A., and Pérez-García, A. 2008. Mechanisms of resistance to QoI fungicides in phytopathogenic fungi. Int. Microbiol. 11:1-9.

8. Fiaccadori, R., Cicognani, E., Alberoni, G., Collina, M., and Brunelli, A. 2011. Sensitivity to strobilurin fungicides of Italian Venturia inaequalis populations with different origin and scab control. Pest Manage. Sci. 67:535-540.

9. Fontaine, S., Remuson, F., Fraissinet-Tachet, L., Micoud, A., Marmeisse, R., and Melayah, D. 2009. Monitoring of Venturia inaequalis harbouring the QoI resistance G143A mutation in French orchards as revealed by PCR assays. Pest Manage. Sci. 65:74-81.

10. Fraaije, B. A., Butters, J. A., Coelho, J. M., Jones, D. R., and Holloman, D. W. 2002. Following the dynamics of strobilurin resistance in Blumeria graminis f. sp. tritici using quantitative allele-specific real-time PCR measurements with the fluorescent dye SYBR Green I. Plant Pathol. 51:45-54.

11. Fraaije, B. A., Butters, J., and Hollomon, D. W. 2000. In planta genotyping of Erysiphe graminis f. sp. tritici isolates for strobilurinresistance using a fluorimetric allele-specific PCR assay. Pages 401-406 in: Proc. Br. Crop Prot. Conf. Pests Dis. 2000. British Crop Protection Council, Farnham, Surrey, UK.

12. Frederick, Z. A., and Cox, K. D. 2012. Practical and qualitative resistance to trifloxystrobin in populations of Venturia inaequalis in the northeastern United States. (Abstr.) Phytopathology 102:S4.42.

13. Gisi, U., Sierotzki, H., Cook, A., and McCaffery, A. 2002. Mechanisms influencing the evolution of resistance to Qo inhibitor fungicides. Pest Manage. Sci. 58:859-867.

14. Ishii, H., Fraaije, B. A., Sugiyama, T., Noguchi, K., Nishimura, K., Takeda, T., Amano, T., and Hollomon, D.W. 2001. Occurrence and molecular characterization of strobilurin resistance in cucumber powdery mildew and downy mildew. Phytopathology 91:1166-1171.

15. Jones, A. L. 1981. Fungicide resistance: past experience with benomyl and dodine and future concerns with sterol inhibitors. Plant Dis. 65:990992.

16. Jones, A. L., and Walker, R. J. 1976. Tolerance of Venturia inaequalis to dodine and benzimidazole fungicides in Michigan. Plant Dis. Rep. 60:4042.

17. Karaoglanidis, G. S., Luo, Y., and Michailides, T. J. 2011. Competitive ability and fitness of Alternaria alternata isolates resistant to QoI fungicides. Plant Dis. 95:178-182.

18. Kim, Y.-S., Dixon, E. W., Vincelli, P., and Farman, M. L. 2003. Field resistance to strobilurin (QoI) fungicides in Pyricularia grisea caused by mutations in the mitochondrial cytochrome $b$ gene. Phytopathology 93:891-900

19. Koenraadt, H., and Jones, A. L. 1992. The use of allele-specific oligonucleotide probes to characterize resistance to benomyl in field strains of Venturia inaequalis. Phytopathology 82:1354-1358.

20. Köller, W. 1991. Fungicide resistance in plant pathogens. Pages 679-720 in: CRC Handbook of Pest Management in Agriculture, vol. 2, 2nd ed. D. Pimentel, ed. CRC Press, Boca Raton, FL.

21. Köller, W. 1999. Chemical approaches to managing plant pathogens. Pages 337-376 in: Handbook of Pest Management. J. R. Ruberson, ed. Marcel Dekker, New York

22. Köller, W. 2003. Fungicides, sterol biosynthesis inhibitors. In: The Encyclopedia of Agrochemicals. J. R. Plimmer, ed. John Wiley, New York.

23. Köller, W., Parker, D. M., Turechek, W. W., Avila-Adame, C., and Cronshaw, K. 2004. A two-phase resistance response of Venturia inaequalis populations to the QoI fungicides kresoxim-methyl and trifloxystrobin. Plant Dis. 88:537-544.

24. Köller, W., and Wilcox, W. F. 2001. Evidence for the predisposition of fungicide-resistant phenotypes of Venturia inaequalis to a preferential selection for resistance to other fungicides. Phytopathology 91:776-781.

25. Köller, W., Wilcox, W. F., Barnard, J., Jones, A. L., and Braun, P. G. 1997. Detection and quantification of resistance of Venturia inaequalis populations to sterol demethylation inhibitors. Phytopathology 87:184190.

26. Lesemann, S. S., Schimpke, S., Dunemann, F., and Deising, H. B. 2006. Mitochondrial heteroplasmy for the cytochrome $b$ gene controls the level of strobilurin resistance in the apple powdery mildew fungus Podosphaera leucotricha (Ell. \& Ev.) E. S. Salmon. J. Plant Dis. Prot. 113:259266.

27. Lesniak, K. E., Proffer, T. J., Beckerman, J. L., and Sundin, G. W. 2011. Occurrence of QoI resistance and detection of the G143A mutation in Michigan populations of Venturia inaequalis. Plant Dis. 95:927-934.

28. Luck, J. E., and Gillings, M. R. 1995. Rapid identification of benomyl resistant strains of Botrytis cinerea using the polymerase chain reaction. Mycol. Res. 99:1483-1488. 
29. Luo, Y., Ma, Z., Reyes, H. C., Morgan, D. P., and Michailides, T. J. 2007. Using real-time PCR to survey frequency of azoxystrobin-resistant allele G143A in Alternaria populations from almond and pistachio orchards in California. Pestic. Biochem. Physiol. 88:328-336.

30. Ma, Z., Felts, D., and Michailides, T. 2003. Resistance to azoxystrobin in Alternaria isolates from pistachio in California. Pestic. Biochem. Physiol. 77:66-74.

31. Ma, Z., and Michailides, T. J. 2004. An allele-specific PCR assay for detecting azoxystrobin-resistant Alternaria isolates from pistachio in California. J. Phytopathol. 152:118-121.

32. Ma, Z., and Michailides, T. J. 2004. A real time PCR assay for the detection of azoxystrobin-resistant Alternaria populations from pistachio orchards in California. Crop Prot. 23:1259-1263.

33. Ma, Z., and Michailides, T. J. 2005. Advances in understanding molecular mechanisms of fungicide resistance and molecular detection of resistant genotypes in phytopathogenic fungi. Crop Prot. 24:853-863.

34. MacHardy, W. E. 1996. Apple Scab-Biology, Epidemiology, and Management. American Phytopathological Society, St. Paul, MN.

35. MacHardy, W. E., Gadoury, D. M., and Gessler, C. 2001. Parasitic and biological fitness of Venturia inaequalis: relationship to disease management strategies. Phytopathology 85:1036-1051.

36. Merwin, I. A., Brown, S. K., Rosenberger, D. A., Cooley, D. R., and Berkett, L. P. 1994. Scab-resistant apples for the Northeastern United States: new prospects and old problems. Plant Dis. 78:4-10.

37. Michalecka, M., Malinowski, T., Broniarek-Niemiec, A., and Bielenin, A. 2011. Real-time PCR assay with SNP-specific primers for the detection of a G143A mutation level in Venturia inaequalis field populations. J. Phytopathol. 159:569-578.

38. Ngugi, H. K., Cox, K. D., Villani, S. M., and Köller, W. 2011. Evidence for multiple fungicide resistance in field populations of Venturia inaequalis. (Abstr.) Phytopathology 101:S128.

39. Olaya, G., and Köller, W. 1999. Diversity of kresoxim-methyl sensitivities in baseline populations of Venturia inaequalis. Pestic. Sci. 55:1083-1088.

40. Olaya, G., Zheng, D., and Köller, W. 1998. Differential responses of germinating Venturia inaequalis conidia to kresoxim-methyl. Pestic. Sci.
54:230-236.

41. Pasche, J. S., Piche, L. M., and Gudmestad, N. C. 2005. Effect of the F129L mutation in Alternaria solani on fungicides affecting mitochondrial respiration. Plant Dis. 89:269-278.

42. Roohparvar, R., De Waard, M. A., Kema, G. H. J., and Zwiers, L.-H. 2007. MgMfs1, a major facilitator superfamily transporter from the fungal wheat pathogen Mycosphaerella graminicola, is a strong protectant against natural toxic compounds and fungicides. Fungal Genet. Biol. 44:378-388.

43. Schnabel, G., Bryson, P. K., Bridges, W. C., and Brannen, P. 2004 Reduced sensitivity in Monilinia fructicola to propiconazole in Georgia and implications for disease management. Plant Dis. 88:1000-1004.

44. Sierotzki, H., Frey, R., Wullschleger, J., Palermo, S., Karlin, S., Godwin, J., and Gisi, U. 2007. Cytochrome $b$ gene sequence and structure of Pyrenophora teres and $P$. tritici-repentis and implications for QoI resistance. Pest Manage. Sci. 63:225-233.

45. Sierotzki, H., Wullschleger, J., and Gisi, U. 2000. Point mutation in cytochrome $b$ gene conferring resistance to strobilurin fungicides in Erysiphe graminis f. sp. tritici field isolates. Pestic. Biochem. Physiol. 68:107-112.

46. Stammler, G., and Klappach, K. 2006. VENTIN spore germination BASF 2006 V1. Fungicide Resistance Action Committee: Monitoring Methods. Online publication. www.frac.info

47. Szkolnik, M., and Gilpatrick, J. D. 1969. Apparent resistance of Venturia inaequalis to dodine in New York apple orchards. Plant Dis. Rep. 53:861864.

48. Vega, B., Liberti, D., Harmon, P. F., and Dewdney, M. M. 2012. A rapid resazurin-based microtiter assay to evaluate QoI sensitivity for Alternaria alternata isolates and their molecular characterization. Plant Dis. 96:1262-1270

49. Zheng, D., and Köller, W. 1997. Characterization of the mitochondrial cytochrome b gene from Venturia inaequalis. Curr. Genet. 38:361-366.

50. Zheng, D., Olaya, G., and Köller, W. 2000. Characterization of laboratory mutants of Venturia inaequalis resistant to the strobilurin-related fungicide kresoxim-methyl. Curr. Genet. 38:148-155. 